\title{
Uma análise da psicodinâmica do trabalho de operadora de caixa de supermercado
}

\author{
Ana Carolina Secco de Andrade Mélou ${ }^{1}$ \\ Universidade Federal do Pará (Belém, PA, Brasil) \\ Paulo de Tarso Ribeiro de Oliveira ${ }^{2}$ \\ Universidade Federal do Pará (Belém, PA, Brasil) \\ Eric Campos Alvarenga ${ }^{3}$ \\ Universidade Federal do Pará (Belém, PA, Brasil) \\ Maria Lúcia Chaves Lima ${ }^{4}$ \\ Universidade Federal do Pará (Belém, PA, Brasil)
}

Trata-se de um estudo qualitativo com base na Psicodinâmica do Trabalho e que analisa o trabalho das operadoras de caixa de supermercado, investigando sua organização e a dinâmica prazer-sofrimento psíquico envolvida. Foram entrevistadas individualmente quinze mulheres, de quatro diferentes supermercados da cidade de Belém-PA, usando roteiro semiestruturado. O material foi examinado conforme a técnica de Análise de Núcleos de Sentido (ANS). Verificou-se uma rígida organização do trabalho das operadoras de caixa de supermercado, contendo poucas possibilidades de transformação do sofrimento em vivências de prazer. Há pouco espaço para as operadoras expressarem as dificuldades do trabalho, tais como: insatisfação com as chefias, falta de reconhecimento no trabalho, assédio sexual, constrangimentos praticados pela clientela e precariedade nas condições de trabalho. A submissão, a crença religiosa e o riso aparecem como estratégias coletivas de defesa para suportar as adversidades do cotidiano laboral.

Palavras-chave: Operadora de caixa de supermercado, Prazer-sofrimento, Psicodinâmica do trabalho.

An analysis of the psychodynamics of a supermarket cash operator work

This is a qualitative study based on Psychodynamic of Work which analyzes the work of supermarket cashiers, investigating its organization and the psychic pleasure-suffering dynamic involved. Fifteen women from four different supermarkets in the city of Belém-PA were interviewed individually, using a semi-structured script. The material was examined according to the Meaning Cores Analysis (MCA) technique. There was a rigid organization of the work of supermarket cashiers, with few possibilities to transform suffering into experiences of pleasure. There is little space for operators to express work difficulties, such as, for example: dissatisfaction with managers, lack of recognition at work, sexual harassment, constraints practiced by the customers and precarious working conditions. Submission, religious belief and laughter appear as collective defense strategies to withstand the adversities of daily routine.

Keywords: Supermarket cashier, Pleasure-suffering, Psychodynamics of work. 


\section{Introdução}

$\mathrm{E}$ ste artigo apresenta uma análise psicodinâmica do trabalho de operadoras de caixa de supermercado na cidade de Belém-PA, investigando a organização e a dinâmica prazersofrimento psíquico envolvida. Destaca-se que o presente artigo é originado da pesquisa de mestrado, vinculada ao Programa de Pós-Graduação em Psicologia da Universidade Federal do Pará (PPGP/UFPA), intitulada Eu acho graça pra não chorar: uma análise da psicodinâmica do trabalho de operadora de caixa de supermercado, de autoria de Ana Carolina Secco de Andrade Mélou, tendo recebido parecer de aprovação pelo Comitê de Ética em Pesquisa (CEP) na data de 6 de julho de 2017, sob o número 2.159.557.

Bendassolli (2009) aponta que desde a Antiguidade, passando pela Idade Média e pelo Renascimento e chegando até a sociedade Industrial, foram cunhadas crenças sobre o valor do trabalho, culminando em sua centralidade social e psicológica a partir do século XIX. Explica, ainda, que por centralidade refere-se à importância que o trabalho assumiu na formação e descrição da identidade humana.

Dejours (2004) em seu artigo intitulado Subjetividade, trabalho e ação expõe que o trabalho pode receber variadas conceituações entre as diferentes disciplinas-sociologia, ergonomia, economia, engenharia, a psicologia. Para alguns, trata-se antes de tudo de uma relação social ou relação salarial; para outros, trata-se do emprego; e para outros ainda, trata-se de uma atividade de produção social.

O trabalho vai para além do simples ato de trabalhar ou de vender a sua força de trabalho para obter a remuneração necessária ao provimento material. Acreditam que ele assume um papel central na constituição da identidade individual e possui implicação direta nas diversas formas de inserção social dos indivíduos. Neste sentido, o trabalho pode ser visto como fundamental na constituição das redes sociais e de trocas afetivas e econômicas, base da vida cotidiana das pessoas (Heloani \& Lancman, 2004).

Seligmann-Silva (2011) aponta que o estudo das repercussões do trabalho sobre a subjetividade humana evoluiu de uma análise focada na situação do trabalho até chegar ao campo da saúde mental do trabalhador e à dimensão psicoafetiva, sendo que a Psicodinâmica do Trabalho (PdT) faz parte deste continuum. A Psicodinâmica do Trabalho (PdT) é uma teoria criada nos anos de 1980, por Dejours (1980). A PdT compõe o conjunto de teorias pertencentes às Clínicas do Trabalho, que têm como foco compreender a relação entre o trabalho, a subjetividade e a intersubjetividade (Bendassolli \& Soboll, 2011). A teoria de Dejours busca compreender os aspectos psíquicos e subjetivos que são mobilizados a partir do confronto do sujeito com a organização do trabalho (Heloani \& Lancman, 2004).

O conceito de sofrimento psíquico é uma das bases do pensamento de Dejours, sendo definido como um estado de luta do sujeito contra as forças que estão empurrando-o em direção à loucura. O sofrimento diz respeito à vivência subjetiva intermediária entre o transtorno mental e o bem-estar psíquico. Trabalhar pressupõe poder tolerar o sofrimento, sendo este a via para superar o obstáculo que se apresenta. $O$ trabalho comporta a dupla polaridade prazer-sofrimento psíquico, sendo que o sofrimento não assume caráter exclusivamente de patologias e dor, uma vez que pode apontar para uma saída saudável e contribuir para a busca de vivências de prazer (Dejours, 2007).

Trabalhar mobiliza a subjetividade, pois o sujeito precisará fazer acréscimos às prescrições para poder atingir os objetivos que lhe são designados, ou acrescentar algo em si mesmo para enfrentar o que não funciona quando ele segue e executa fielmente as prescrições (Dejours, 2004).

Estudos sobre a análise do trabalho de operadoras de caixa verificaram algumas características comuns. O comércio varejista é um dos responsáveis pela manutenção da exploração da força de trabalho feminina, pois a mulher é comumente contratada para cargos como o de operadora de caixa e de atendimento em geral, nos quais é exigida a constante atenção, prestação de serviço com qualidade e saber contornar as situações de insatisfação dos clientes (Cardoso, 2015). Para Falquet (2016), uma parte crescente do trabalho habitualmente 
atribuído às mulheres parece sair do contexto conjugal-familiar para ser realizado de maneira remunerada no mercado de trabalho.

As pessoas que trabalham na operação do caixa de supermercado costumam apresentar queixas musculoesqueléticas (Teixeira et al., 2009), que podem estar relacionadas ao fato de o trabalho ser desenvolvido em balcões que não são adaptados às diferenças antropométricas individuais de cada trabalhador(a) (Trelha \& Carregaro, 2017), trazendo à tona, assim, a necessidade de adaptações dos postos de trabalho (Gomes et al., 2011). Neste contexto, a relação com o cliente é fundamental, pois dita o ritmo e velocidade do seu trabalho (Santos, 2004).

O trabalho em supermercados possui baixos níveis de motivação entre trabalhadoras e trabalhadores (Martins et al., 2010), certa cobrança de seguir a fórmula "Sorrir. Bom dia. Tchau. Obrigado", promovendo constantemente a imagem do supermercado (Barel \& Frémeaux, 2010) e respeitando regras rígidas quanto às vestimentas e modos de apresentação pessoal (Soares, 2014).

A escuta do sofrimento relacionado ao trabalho, a partir do referencial da Psicodinâmica do Trabalho, tem crescido na Amazônia, especialmente nos programas de pós-graduação das universidades federais. Na Universidade Federal do Pará, há produção de artigos científicos, dissertações e teses, oriundos de grupos como os do Programa de Pós-Graduação em Psicologia, do Programa de Pós-Graduação em Serviço Social e do Programa de Pós-Graduação em Desenvolvimento Sustentável do Trópico Úmido do Núcleo de Altos Estudos Amazônicos (Moraes et al., 2019). Assim, a presente pesquisa veio somar-se a este conjunto de produções da UFPA e de outras universidades brasileiras. A seguir, este artigo apresentará o método, os resultados e discussão, por fim, a conclusão.

\section{Método}

A Psicodinâmica do Trabalho (PdT) se insere no âmbito da pesquisa qualitativa e busca compreender os aspectos psíquicos e subjetivos que são mobilizados a partir do confronto do sujeito com a organização do trabalho, estudando os aspectos menos visíveis que são vivenciados pelos/as trabalhadores/as. Para tanto a PdT utiliza um método que liga a pesquisa à intervenção, pautado nos princípios da pesquisa-ação (Heloani \& Lancman, 2004).

Participaram desta pesquisa 15 mulheres ocupantes e ex-ocupantes do cargo de operadora de caixa de quatro diferentes supermercados da cidade de Belém-PA. Este número total de entrevistas foi definido durante o trabalho de campo e pautou-se no critério de ponto de saturação, o qual postula que, em um dado momento, percebe-se que não mais aparecem informações ou sentidos novos no conteúdo das falas das entrevistadas. Este ponto de saturação do sentido pode ser tomado como um indicativo de que é hora de encerrar as entrevistas (Bauer \& Gaskell, 2011).

Para ter acesso às operadoras de caixa foram exploradas duas vias: a Associação Paraense de Supermercados (ASPAS) e o Sindicato dos Trabalhadores de Supermercado de Belém (SINTCVAPA), sendo através deste último que foi possível o trabalho de campo. Ao sindicato foi solicitada autorização para abordar operadores(as) de caixa que se encontrassem na recepção da sede, para fazer-lhes o convite de participação na pesquisa. $O$ sindicato aceitou a solicitação e disponibilizou uma sala para que as entrevistas fossem conduzidas. A parceria com o sindicato foi pensada porque vários trabalhadores e trabalhadoras comparecem diariamente lá para usar os serviços ofertados, como: consultas odontológicas, pegar encaminhamento médico para outras especialidades, assessoria jurídica e também para realizar a homologação da rescisão de contrato de trabalho de funcionários e funcionárias com mais de um ano de vínculo empregatício e que haviam saído de suas empresas. Vale destacar que esta pesquisa foi realizada antes da reforma trabalhista sancionada no ano de 2017. Atualmente, não há mais esta obrigatoriedade de homologar rescisão de contrato de trabalho na sede do sindicato.

É relevante informar que não havia uma definição prévia de entrevistar somente mulheres. Contudo, durante os dias de permanência em campo foi possível identificar o 
comparecimento ao sindicato somente de ocupantes mulheres do cargo de operadora de caixa. Esta predominância de mão de obra feminina neste cargo será objeto de discussão mais adiante. As trabalhadoras foram convidadas a participar e integraram esta pesquisa somente as que aceitaram o convite voluntariamente e mediante assinatura do Termo de Consentimento Livre e Esclarecido (TCLE).

Foi utilizado um roteiro de entrevista semiestruturado. A entrevista é uma técnica de coleta de dados, centrada na relação pesquisadores-pesquisados e na fala-escuta-fala dos conteúdos manifestos e latentes, sobre a organização do trabalho, as vivências de prazersofrimento, as mediações, e os processos de subjetivação e de saúde-adoecimento. O momento da entrevista é um processo no qual os vínculos (simbólicos, afetivos, ideacionais e sociais) são estabelecidos. À medida que o entrevistado fala, o entrevistador escuta e se envolve no discurso do entrevistado, buscando apreender os conteúdos latentes. A entrevista quando usada em pesquisas com referencial na Psicodinâmica do Trabalho, deve ter a escuta como premissa básica, ou seja, o entrevistador deve ter seu foco na lógica do entrevistado (Mendes, 2007).

Para a seleção das participantes, foi utilizado o critério de inclusão de experiência de trabalho mínima de um ano como operadora de caixa de supermercado. É relevante destacar que, como a via de acesso às operadoras de caixa se deu através do sindicato, estas compareciam ao local sem prévio agendamento e em horários e dias variados, bem como pertenciam a supermercados variados e tinham diferentes disponibilidades de tempo para conceder a entrevista, o que impossibilitou a realização de entrevistas em grupo com as operadoras.

A entrevistada com menos tempo de atividade no cargo trabalhou um ano como operadora de caixa de supermercado, ao passo que a mais experiente já somava 10 anos no cargo. Todas as entrevistadas afirmaram ser a primeira vez que trabalhavam ou que haviam trabalhado como operadoras de caixa de supermercado, e para cinco delas este foi também o primeiro emprego. Todas possuíam escolaridade de ensino médio completo. A operadora de caixa mais jovem possuía 21 anos e a de maior idade estava com 50 anos.

Após a transcrição de todas as entrevistas, realizou-se uma primeira leitura para definir qual material iria compor as análises. Fez-se uma segunda leitura das entrevistas, para os procedimentos de análise e discussão. As discussões se basearam nas proposições de Mendes (2007) sobre o conceito de Análise de Núcleo de Sentidos (ANS), o qual consiste em uma adaptação da técnica desenvolvida por Bardin (2011). A ANS tem por finalidade agrupar o conteúdo latente e manifesto do texto, com base em temas constitutivos de um núcleo de sentido. Assim, o conteúdo das entrevistas permitiu apreender os sentidos expressos nas falas das operadoras de caixa. Por meio dos núcleos de sentido extraídos das verbalizações das participantes, foi possível ter acesso ao conteúdo necessário para analisar a organização do trabalho de operadora de caixa de supermercado e a dinâmica prazer-sofrimento psíquico envolvida.

Antes da finalização da pesquisa foi realizada uma validação e devolutiva às operadoras de caixa participantes. O objetivo foi de apresentar para as operadoras as análises realizadas a partir dos conteúdos expressos nas entrevistas, a fim de que elas pudessem expor suas opiniões, validar ou refutar o que foi escrito no texto das análises.

\section{Resultados e discussão}

Na escrita dos resultados e discussão fez-se uma articulação entre os conceitos da psicodinâmica do trabalho e os respectivos núcleos de sentidos que emergiram das falas das operadoras. Ademais, percebeu-se a necessidade de abordar a questão da divisão sexual do trabalho de forma mais específica. Neste sentido, Margaret Maruani (2018), na obra Je travaille, donc je suis: perspectives féministes ${ }^{5}$, afirma a pertinência constante de considerar o conceito de gênero na análise do mundo do trabalho, a fim de revelar tais clivagens sociais. Gênero pode ser 
compreendido como um elemento constitutivo das relações sociais, que se baseia nas diferenças percebidas entre os sexos, bem como um fundamento para significar as relações de poder em nossa sociedade, ou seja, o gênero é entendido como uma criação inteiramente social das identidades subjetivas de homens e mulheres (Scott, 1995).

\section{As condições de trabalho}

As condições de trabalho se referem às condições físicas, químicas e biológicas do ambiente de trabalho (iluminação, sonoridade, odores, manipulação de produtos, fumaça, vapores, poeira, bactérias, fungos) e as condições de higiene e de segurança (Dejours, 2015). As entrevistadas relataram situações acerca das condições de trabalho causadoras de insatisfação. Assim, tem-se quanto às condições de trabalho os núcleos de sentidos: "A esteira não funciona"; "As cadeiras não são adequadas" e "A água não é boa".

"A esteira não funciona": Nos checkouts (balcões dos caixas), foram destacados problemas de funcionamento na esteira. A esteira inoperante gera dificuldades no trabalho da operadora, pois ela se vê obrigada a fazer mais movimentos, tais como esticar os braços e puxar ou levantar produtos pesados, o que ocasiona mais desgaste físico e torna o dia de trabalho mais exaustivo, principalmente quando há fluxo intenso de clientes na loja. Por vezes, o cliente aceita ajudar a colocar os produtos mais para perto para que a operadora não seja obrigada a se levantar, mas isso também ocasiona dificuldades, pois os clientes acabam por despejar reclamações e ter comportamentos hostis dirigidos a elas.

"As cadeiras não são adequadas": Todas as operadoras reclamaram das cadeiras inadequadas oferecidas pelos estabelecimentos. Relataram que, às vezes, sentam-se em cadeiras velhas, com o encosto quebrado e com assento rasgado. Elas falaram que há cadeiras novas, mas que não são confortáveis. Em função disso, as queixas de dores e desconforto na coluna foram unânimes entre as entrevistadas. Dentre as quinze operadoras participantes desta pesquisa, quatorze mencionaram problemas físicos em função das atividades e/ou condições de trabalho. As queixas referidas foram: dores na coluna, nas mãos/punhos, nos braços, no pescoço e no estômago, dificuldades na visão e enxaqueca. Teixeira et al. (2009) realizaram estudo no qual 48 operadores de um supermercado em Santa Catarina se referiram a queixas similares de saúde em função do trabalho.

Trelha e Carregaro (2017) afirmam que os operadores de caixa exercem suas atividades em balcões que possuem designs com medidas e formatos padronizados e que, portanto, não consideram e não são adaptados às diferenças antropométricas individuais de cada trabalhador(a), como peso e altura. O padrão de movimento e as posturas adotadas durante o período de trabalho, associados à inadequação do posto, podem contribuir para a sobrecarga física do sistema musculoesquelético, o que acaba por predispor estes(as) trabalhadores(as) à incidência de problemas de saúde predominantemente nas regiões da coluna lombar, ombros e punhos. Outro estudo, realizado por Gomes et al. (2011) com operadores de caixa de supermercado na cidade de Alegre-ES, ressalta a necessidade de alterações do posto de trabalho e os impactos deste para a saúde física das trabalhadoras operadoras de caixa. Os autores propõem intervenções como a mudança da posição do teclado e do computador e a necessidade de atividades e informações ergonômicas aos operadores de caixa, junto a inserção de ginástica laboral ao início da jornada de trabalho.

"A água não é boa": As entrevistadas expressaram reprovação quanto à qualidade da água disponibilizada pela empresa para o consumo delas, e relacionaram a esta água consequentes situações de mal-estar de saúde e problemas gástricos e intestinais, fazendo com que elas optem por levar a sua própria água de casa.

O que não é bom é a água lá que é oferecida. Não é mineral. Tem um bebedouro que fica lá pros funcionários. Só que eu tive problema lá com essa água também. Por causa dessa água, que eu percebi. Porque em casa a gente bebe água mineral. Mas quando eu comecei a trabalhar lá, eu comecei a sentir umas coisas estranhas: enjoo. Até o gosto é meio diferente. Então, parece uma 
ferrugem, alguma coisa assim. Às vezes umas coisinhas pretas que a gente vê lá. Então, quando eu comecei a consumir aquela água lá, comecei a ter problemas com isso e eu percebi que era a água ... diarreia. Tem dois anos que eu não bebo a água de lá, eu levo. Aí pronto, eu não senti mais dor. Eu tenho pavor de tomar aquela água, eu não tomo não (Entrevistada 5).

\section{A organização do trabalho}

A organização do trabalho é definida como a divisão das atividades, o conteúdo da tarefa, os procedimentos e ritmo de trabalho, o sistema de hierarquia que norteia a relação humana com os pares, com os subordinados e com a chefia, bem como as questões de comando e de poder envolvidas (Dejours, 2015). Quanto à organização do trabalho, os núcleos de sentidos identificados foram: "Devolução"; "A gente tem que embalar"; "Quase sempre passa do horário"; "A gente assina vale"; "Só mulher operando o caixa"; "Tinha que tá bem arrumadinha"; "Por mais que tu estejas triste, tu tens que tá feliz" e "O difícil é a nossa encarregada".

"Devolução": O cotidiano laboral das entrevistadas se mostrou bem desgastante, pois, além das atividades específicas do cargo de operadora de caixa, a rotina de trabalho é acrescida da execução de outras atividades, como embalar as compras e fazer "devolução" de produtos que os clientes desistem de comprar e acabam abandonando no caixa. Desse modo, as operadoras de caixa acabam por fazer parte do contingente de funcionários(as) utilizado para fazer a devolução destes produtos às prateleiras na área de venda.

"A gente tem que embalar": A obrigação de embalar mercadorias repercute negativamente na saúde das operadoras, pois além das queixas físicas, a constância desta atividade é significativa fonte de sofrimento psíquico, uma vez que as trabalhadoras são cobradas pela agilidade no atendimento. A execução simultânea de duas atividades acaba tornando o andamento da fila mais lento, gerando reclamações dos clientes e dando vazão a agressões direcionadas a elas. Vale lembrar que Santos (2004) aponta o cliente como elemento fundamental no trabalho da operadora de caixa de supermercado, pois é ele que dita o ritmo e velocidade do seu trabalho, que é influenciado pelo tamanho da fila no caixa.

As entrevistadas não concordam em ter que realizar outras atividades que não fazem parte do escopo do cargo, mas relataram que as fazem pelo receio de que a recusa possa colocálas em uma situação de instabilidade no trabalho. Desta forma, a precarização do trabalho impõe a flexibilização das atividades às operadoras de caixa, pois as trabalhadoras devem ser polivalentes. Dejours (2000) aponta que a precarização do trabalho traz como consequências a sua intensificação e o aumento do sofrimento subjetivo, bem como a neutralização da mobilização coletiva contra o sofrimento e a dominação. $O$ que se percebe é que a imposição à operadora de caixa de ter que embalar as mercadorias ocorre por várias razões: o quadro deficiente de embaladores mantido pela empresa, a demanda direta das chefias para que elas embalem e a pressa dos clientes. Este cenário espelha uma precarização do trabalho, fazendo com que as operadoras sejam pressionadas e cobradas em demasia, causando-lhes sobrecarga física e sofrimento psíquico. É importante ressaltar, ainda, que a função de embalar a mercadoria é uma realidade regional, pois em várias cidades brasileiras esta é uma responsabilidade do(a) cliente. As operadoras apontaram que um dia de trabalho tranquilo se dava quando não precisavam embalar e podiam ficar registrando as mercadorias, ou seja, a atenuação dos fatores de precarização do trabalho.

"Quase sempre passa do horário": Outro ponto relatado é referente à jornada de trabalho, não somente pelo constante atraso no horário de saída, mas também pelo atraso na ida para o intervalo, o que foi apontado como um prejuízo à alimentação, fator gerador de cansaço físico e de problemas gástricos. Embora as operadoras sejam cientes de que há dias de maior movimento e que nestes dias provavelmente terão que fazer hora extra, a insatisfação reside no fato de afirmarem que, rotineiramente, há o prolongamento da jornada de trabalho, o que acarreta um cansaço a mais com o decorrer dos dias. 
"A gente assina vale": Além disso, responsabilidade em trabalhar manipulando o dinheiro que não lhe pertence e ainda ter que fazer outras atividades simultâneas, como embalar e lidar com os clientes, causa receio e apreensão nas operadoras sobre possíveis faltas de dinheiro em seu caixa. As entrevistadas afirmaram com bastante pesar a obrigação de ressarcir os valores a menor em seu caixa, pois todo valor que faltar no caixa é de responsabilidade da operadora, bem como o recebimento de cédulas de dinheiro ou tickets falsos. Há também situações em que o fechamento do caixa acusa a sobra de dinheiro. Nesses casos, as trabalhadoras demonstraram insatisfação porque esse dinheiro não é utilizado para suprir as faltas de caixa, o que evitaria que elas fossem sempre obrigadas a ressarcir a empresa.

"A gente é muito maltratada pelos clientes": O conteúdo sobre a relação com a clientela esteve presente na totalidade das falas, mostrando fortemente que tal relação pode ser fonte de conflitos, frustrações, constrangimentos e sofrimento psíquico relacionado ao trabalho.

O trabalho de operadora de caixa não é muito valorizado pela maioria das pessoas que vão no supermercado, porque os clientes vão no supermercado ... sei lá, eles se acham superiores que a gente só porque eles estão comprando. Eles querem pisar, humilhar a gente. Às vezes, tem coisas dentro do supermercado que acontecem na peixaria ou em outro setor que eles vêm tudo descontar na gente. Eles pensam que tudo é culpa da operadora e já chegam no caixa reclamando (Entrevistada 8).

A não reação das trabalhadoras frente a estas vivências de constrangimentos e hostilidade dos clientes, há também o fato que elas mesmas informaram que "devem evitar" fazêlo pela necessidade de manter o emprego. Dejours (2000) atribuiu o surgimento do medo e submissão, em seu livro A banalização da injustiça social, justamente pelo risco da demissão. Assim, as trabalhadoras se veem obrigadas a "aceitar" tais situações, ou seja, ficam passivas em função da possibilidade de sofrer sanções e ameaças de perda do emprego, o que certamente contribui com o aumento do sofrimento psíquico relacionado ao trabalho.

Percebe-se que a organização do trabalho não lhes confere autonomia para expressar seus sentimentos mediante tais situações com a clientela, uma vez que as operadoras não devem ter comportamentos que representem uma reação de desagrado e devem continuar a atender da "melhor forma", para que o cliente deixe o supermercado satisfeito. Waelli e Fache (2013), no artigo La régulation de l'emploi dans les hypermarchés français, reiteram que o trabalho em supermercados possui a imagem cada vez mais negativa, o que se evidencia por estudos epidemiológicos que o qualificam negativamente quanto à saúde mental no trabalho.

Martins et al. (2010), na pesquisa $O$ enfermeiro do trabalho e o transtorno depressivo em operadoras de checkout, um estudo com operadores de caixa de três supermercados da cidade de Curitiba-PR, apontaram que somente $28 \%$ dos(as) participantes mencionaram motivação para trabalhar. A desmotivação foi apontada em razão do salário baixo $(23 \%)$, da falta de reconhecimento $(15 \%)$, da indelicadeza dos clientes do supermercado $(14 \%)$ e da falta de perspectivas futuras (12\%). Do total de participantes, 39\% referiram sintomatologia compatível com transtorno depressivo na maior parte do dia e todos os dias, tendo assinalado mais de três sintomas simultaneamente. As autoras concluíram que a incidência dos sintomas está relacionada às condições laborais dos(as) operadores(as). Desta forma, a coincidência entre as informações apontadas no referido estudo e o conteúdo expresso pelas operadoras de caixa entrevistadas na presente pesquisa corrobora com a necessidade de olhar a questão da saúde mental desta categoria de trabalhadoras.

"Só mulher operando o caixa": Deve-se destacar, também, a divisão sexual do trabalho presente no setor supermercadista. Hirata e Kergoat (2007) afirmam que a divisão sexual do trabalho é uma forma de divisão social com base na separação entre trabalhos de homens e trabalhos de mulheres, a qual é moldada historicamente. Nessa divisão, cabe aos homens o trabalho pertinente à esfera produtiva e com maior valor social. Já para as mulheres cabe o trabalho de característica reprodutiva e subordinado. No estudo Perspectivas sociales y del empleo en el mundo: avance global sobre las tendencias del empleo femenino 2018 (Organização Internacional do Trabalho, 2018), é proposto um enfoque mais amplo para compreender as problemáticas das 
mulheres no mundo do trabalho, considerando não só as desigualdades de gênero, mas também as variações de classe, etnia e idade, para se obter um alcance mais amplo desta temática. Este estudo ainda sugere que a solução dos problemas que assolam as mulheres no mercado de trabalho necessitará de esforços dos governos, dos empregadores, dos sindicatos, bem como mudanças culturais na forma de enxergar o trabalho feminino. Antunes (2018) também corrobora com a importância de se considerar a relação entre gênero, classe, etnia e geração, a fim de compreender e fazer desmoronar o mito que envolve o trabalho feminino dentro das fábricas, indústrias, call-centers e hipermercados.

"Tinha que tá bem arrumadinha": A predominância de mulheres operando os caixas de supermercados também apontou para uma instrumentalização do corpo da trabalhadora, uma vez que sobre a imagem dela é colocada a responsabilidade de transmitir uma boa imagem da empresa. Neste sentido, as trabalhadoras devem manter uma aparência "atraente", "agradável". Há, inclusive, regras de aparência pessoal para operadoras de caixa de supermercado, tais como usar maquiagem, brincos e batom discretos. As trabalhadoras estão sujeitas a repreensão pela chefia caso não obedeçam a tais regras de apresentação impostas pela empresa (Soares, 2014).

Dentre as diversas formas de violência ocorridas no mundo do trabalho, será aqui abordado o assédio sexual, por assumir um papel significativo na experiência laboral das funcionárias entrevistadas. As operadoras falaram do assédio sexual que existe no âmbito do trabalho em supermercados, bem como enquadraram essa prática como uma espécie de condição que possibilitaria a promoção para outro cargo.

Falta oportunidade pra certas pessoas que merecem e o gerente não dá. Tu tem que ... vou falar assim o português claro, tu tem que sair com o gerente pra tu passar de cargo, pra tu crescer, pra tu ter oportunidade lá na empresa. Lá é assim que funciona. Não é por teu merecimento! (Entrevistada 2).

Diniz (2014), em estudo sobre o assédio sexual vivenciado por trabalhadoras do comércio, afirma que, embora o assédio sexual possa ocorrer entre os pares, há prevalência deste tipo de assédio nas relações que implicam alguma hierarquia. Os assédios moral e/ou sexual foram identificados como fatores que potencializam a precarização do trabalho feminino, gerando, nas trabalhadoras, muito medo de serem perseguidas, caso denunciem o ocorrido. Barreto (2014) indica que seria válido difundir o conceito de assédio sexual entre os(as) trabalhadores(as) e declarar objetivamente que a empresa não aceita a prática de violências no trabalho. Seria igualmente importante garantir o direito à denúncia e à privacidade mediante tais casos e, certamente, estas medidas devem somar-se a uma reflexão sobre a organização do trabalho.

"Por mais que tu estejas triste, tu tens que tá feliz": Um outro aspecto importante no trabalho é a obrigação que a operadora tem de sorrir, sendo o sorriso considerado como fundamental para um atendimento de qualidade. Essa imposição acaba por se tornar mais um fardo para as trabalhadoras, pois elas se veem obrigadas a negligenciar seus sentimentos e desconfortos para não serem mal avaliadas em seus atendimentos. A obrigação de sorrir aparece como uma imposição característica do setor supermercadista em geral. No artigo Organisation du travail et démarche qualité: le cas du secteur caisses d'un hypermarché, Barel e Frémeaux (2010) apontam que às operadoras de caixa de um supermercado francês é cobrado o respeito à fórmula SBAM (Sorrir. Bom dia. Tchau. Obrigado), havendo também uma acentuação da dimensão relacional do trabalho para a promoção da imagem do supermercado.

Não é fácil tá sentada lá atendendo, com uma roupa quente. A gente tá com problema em casa. Às vezes, a gente tá com uma dor no corpo e tu tens que tá lá, sabe? Tipo, tu és obrigada a sorrir. Tu és obrigada a atender, a mostrar que tudo tá bem. Se tiver com cara feia o cliente ou a chefe vai logo reclamar. Tipo, a gente sofre uma pressão nisso porque por mais triste que tu estejas, tu tens que tá feliz. Tu tens que mostrar que tá feliz (Entrevistada 8).

"O difícil é a nossa encarregada": Sobre a relação com as chefias, várias operadoras expressaram em suas entrevistas o pouco espaço existente para diálogo e a falta de compreensão 
por parte das chefias. Os gerentes, encarregados e fiscais de caixa foram criticados pelo uso abusivo da autoridade, pela prática de muita cobrança e controle. As operadoras expuseram que não se sentem compreendidas em suas necessidades e, muitas vezes, se percebem sem apoio. Ademais, sobre a necessidade de ir ao banheiro, as entrevistadas indicaram, inicialmente, que não havia impedimento ou restrição de acesso. Porém, ao se prolongarem nas respostas, afirmaram saber que é "melhor evitar" pedir sucessivas vezes para ir e quando vão, precisam fazêlo apressadamente.

$\mathrm{Na}$ ida ao banheiro a gente tem que pedir. Às vezes eles fazem a gente esperar muito. Aí, a gente fica se prendendo ... Se tu queres ir tu vais, mas eles (fiscais de caixas e encarregados) não gostam. Aí, tu demoras um pouquinho, eles vão atrás de ti, ficam falando que tu estás "enrolando". Pode sair o tanto que quiser, mas todo mundo vai geralmente só uma vez porque eles não gostam. Tipo assim: se a minha colega for, eu tenho que esperar ela voltar pra eu poder ir (Entrevistada 15).

\section{Estratégias coletivas de defesa e resistência}

Dejours (2012) aponta que o sujeito, por sua vez, não é passivo em relação às situações geradoras de sofrimento no trabalho. Assim, tem-se o conceito de estratégias coletivas de defesa, as quais são construídas com o esforço conjunto dos(as) trabalhadores(as) na tentativa de afastar os efeitos desestabilizadores presentes na organização do trabalho. Tais estratégias representam a vontade de reverter simbolicamente a internalização do risco - fator gerador de sofrimento no trabalho -, promovendo uma eufemização coletiva da percepção ou mesmo a negação do risco (Dejours, 2012). Os núcleos de sentido relacionados às estratégias coletivas de defesa foram expressos nas frases: "Eu acho graça pra não chorar" e "Eu só orava a Deus e pedia força"

"Eu acho graça pra não chorar": Os risos, e por vezes, breves gargalhadas, foram uma constante na expressão das entrevistadas e nos relatos. Esse comportamento ocorreu desde o momento da abordagem inicial às operadoras. A primeira operadora abordada na recepção do sindicato para ser convidada a participar da pesquisa, falou aos risos: "você quer saber das operadoras de caixa? Elas estão tudo loucas". E, posteriormente, aceitou participar e assim foi realizada a primeira entrevista no dia 31 de outubro de 2017.

O riso se fazia presente na expressão das operadoras quando relatavam as dificuldades e o sofrimento no trabalho, como quando falavam sobre os constrangimentos praticados pelas chefias, os embates com os clientes, sobre a falta de reconhecimento no trabalho, a precarização das condições de trabalho e as pressões e cobranças. Esta estratégia coletiva de defesa ficou ainda mais emblemática quando uma das operadoras proferiu a frase "Eu acho graça pra não chorar". Por vezes, o riso era acompanhado de expressões como "Ai, ai ...." ou "Hum". Esses momentos foram muito significativos, pois mostraram o quanto aquele conteúdo da entrevista era mobilizador de sofrimento psíquico para as operadoras e, na impossibilidade de mudar isso, o riso era usado por elas como uma forma atenuante de poder lidar com a situação.

"Eu só orava a Deus e pedia força": As entrevistadas também recorrem às suas crenças religiosas como forma de se proteger e suportar as adversidades vivenciadas no exercício laboral. No texto O Futuro de uma ilusão, Freud ([1926-1929] 2014) menciona a religião como talvez o mais importante elemento do inventário psíquico de uma cultura, no sentido de que as ideias religiosas dão conta de justificar as ilusões. Assim, compensar as angústias e sofrimentos ocasionados uns aos outros em nossas relações passa a ser uma tarefa divina, justificando o apego à crença religiosa como forma de amenizar o sofrimento.

Eu tenho que orar muito e pedir a Deus pra me iluminar muito pra não falar besteira, porque eu preciso do emprego. Pra empresa também não dizer que a gente tem que se calar pro cliente. A gente não pode se calar pro cliente, mas a gente releva, não discute com o cliente (Entrevistada 11). 
Como já destacado na metodologia, devido à peculiaridade do campo, não foi possível a realização de entrevistas coletivas com as operadoras de caixa. Todavia, mesmo o trabalho de campo tendo ocorrido com entrevistas individuais, considerou-se o riso e a menção à crença religiosa como expressões de estratégias coletivas de defesa, uma vez que foram manifestações unânimes nas falas das entrevistadas. Assim, entendeu-se que o uso do riso e da religião frente às situações mobilizadoras de sofrimento perpassava uma esfera coletiva entre as trabalhadoras. A religião e resignação também surgiram como estratégias coletivas de defesa em recente estudo realizado por Flores e Moura (2018), ao afirmarem que o grupo de trabalhadores investigado buscava suporte na expressão da religiosidade e em formas "silenciosas" de apoio mútuo mediante a realidade do trabalho.

Ter que manter o emprego é uma das razões que levam as entrevistadas a tolerar as dificuldades. Nesse contexto, "aguentar" e "aturar" foram palavras recorrentes nos relatos. A necessidade de "aguentar" se expressou por várias questões: pelo fato de a operadora ser a única pessoa com renda fixa da casa, nos casos em que o companheiro trabalhava fazendo "bico" (trabalho informal). O sustento dos filhos foi outra razão, bem como a idade e o receio de não encontrar outra oportunidade de trabalho facilmente, além da necessidade do salário para pagamento de despesas com faculdade privada.

Nos relatos também foram evidenciadas ações de resistência por parte das entrevistadas, pois as operadoras também evidenciaram formas de lidar com as adversidades e o sofrimento inerentes ao seu trabalho, as quais se aproximam mais de um caráter de resistência, não no sentido psicanalítico, mas no sentido de enfrentamento das dificuldades oriundas da organização do trabalho. Seligmann-Silva (2011), ao fazer a diferenciação entre os termos defesa e resistência, ressalta que a diferença essencial é que a defesa serve basicamente para evitar ou tornar suportável o sofrimento, e não propicia a transformação; enquanto as resistências visam modificar as situações geradoras de sofrimento. Então, quando o sujeito defende sua autonomia e seu pensamento, está agindo em defesa de sua identidade, logo esta defesa pode se revestir de resistência, de enfrentamento.

Mediante as pressões vivenciadas pelas operadoras de caixa e aliado ao uso de defesas, algumas trabalhadoras expressaram ações de resistência frente à dominação e precarização do trabalho. Todavia, no cotidiano, estas resistências e enfrentamentos se davam de forma individual.

Quando eu queria, eu fazia hora extra. Eu já não tava mais ficando porque não tava compensando. Porque geralmente eles não pagam hora extra, é banco de horas. Aí, eu tava deixando de trabalhar porque não tava valendo a pena (Entrevistada 4).

A recusa em passar do horário de trabalho pré-estabelecido e em acumular a atividade de embalar mercadorias foi citada por algumas trabalhadoras. Falar e reclamar às chefias sobre as dificuldades também foi uma forma de resistência, mesmo sendo avaliado pelas trabalhadoras como uma possibilidade que não gera mudanças efetivas.

\section{Prazer e reconhecimento no trabalho}

O trabalho pode, também, fornecer à pessoa reconhecimento, uma retribuição simbólica valiosa, que constitui um importante fator para vivências de prazer e manutenção da saúde mental do(a) trabalhador(a) (Dejours, 2007). O reconhecimento representa a possibilidade de transformar o sofrimento em prazer nas atividades de trabalho, beneficiando o registro da identidade, naquilo que torna o(a) trabalhador(a) único(a) (Dejours, 2009).

Ao pesquisar operadoras de supermercado na França, Benquet e Nathalie (2009) teve acesso a falas que corroboram com os apontamentos no presente artigo. Segundo uma trabalhadora francesa, ser operadora de caixa é considerado difícil, uma vez que a rotina se instala 
facilmente, impedindo o aprendizado de outras atividades e, ainda, devido à constante preocupação de não cometer erros.

"O que eu gosto no meu trabalho? Como assim?" Foi assim que uma entrevistada reagiu, demonstrando surpresa, à pergunta feita sobre o que ela gostava em seu trabalho. Sentir prazer naquele trabalho era realmente algo no qual algumas daquelas mulheres pensavam ser pouco possível. De forma geral, as operadoras não julgavam o trabalho como uma atividade prazerosa, sendo qualificado como uma obrigação, uma necessidade, falta de opção e até um prejuízo à saúde.

De acordo com Mendes (2007), mesmo em um contexto de trabalho precário, é possível que os sujeitos vivenciem o prazer, caso a organização do trabalho ofereça possibilidades de construção de um espaço público de fala. Tais afirmações corroboram com as mudanças que as operadoras entrevistadas sugeriram: oportunidade de serem escutadas pelas chefias sobre as dificuldades existentes em seu trabalho e a oferta de mais possibilidades de promoção e aprendizado por parte da empresa.

Os núcleos de sentido referentes ao prazer no trabalho apontados pelas operadoras entrevistadas foram: "Eu gosto dos meus colegas de trabalho" e "A gente conhece cada pessoa bacana". Já quanto ao reconhecimento, identificou-se os núcleos: "Eles não dão valor nas coisas que a gente faz" e "Falta oportunidade".

"A gente conhece cada pessoa bacana": Apesar de raras, houve referências de prazer no contexto laboral. Embora a relação com a clientela tenha sido majoritariamente referenciada como uma dificuldade, o relacionamento com os "bons clientes" foi citado como fonte de prazer no trabalho, sobretudo, com os clientes idosos. Estes foram apontados como os que mais gostam de conversar com as operadoras. Assim, conhecer estas pessoas também pode tornar o trabalho gratificante.

"Eu gosto dos meus colegas de trabalho": Outra forma de vivência de prazer no trabalho citada, por todas as participantes, foi a relação e convivência com os(as) colegas de trabalho, exemplificando momentos como os de conversa sobre o trabalho e suas vidas ou ir junto para o intervalo da refeição.

"Eles não dão valor nas coisas que a gente faz": Todavia, sobre o reconhecimento no trabalho, as operadoras relataram não se sentirem reconhecidas, o que se desvelou em função de quatro razões: pela ausência de elogio por parte das chefias quanto ao trabalho realizado; pela não oferta de brindes ou premiações como recompensa pelo bom trabalho executado; pela falta de comemorações voltadas às funcionárias em épocas festivas e pela ausência de uma política de oportunidades internas capaz de promover o aprendizado de outras atividades, ascensão funcional e a progressão salarial. A ausência do reconhecimento, somado a tudo que já foi explicitado, ocasiona a desmotivação das trabalhadoras e a vivência de um trabalho esvaziado de sentido.

É um desanimo por tudo isso que eu lhe falei. Infelizmente não é como eu esperava. A pessoa de fora acha que é tudo bonito, tudo legal, tudo tranquilo. Tanto é que quando eu fui fazer a entrevista e que eu passei, aí no final eles fazem uma palestra falando que a gente tá entrando numa coisa maior, de maior porte e lalalá ... Então, eles falam uma coisa ali que parece que é um paraíso. E quando você realmente começa a trabalhar e vê que a situação é totalmente diferente. Então, eu fiquei muito decepcionada. Na verdade, a palavra é essa: decepção. Não me sinto reconhecida pela empresa. Na verdade, não sou só eu, são todas que estão lá (Entrevistada 5).

"Falta oportunidade": Segundo as entrevistadas, a falta de uma política transparente de promoção também abre espaço para o julgamento pessoal por parte das chefias sobre que operadora receberá uma oportunidade de assumir outro cargo. Este tratamento desigual mostrou ser fonte de ressentimento e raiva entre as operadoras. Sobre isso, Waelli e Fache (2013) indicaram que o supermercado não demonstra dedicação em reconsiderar a organização concernente ao trabalho de operadora de caixa. Assim como as operadoras, outros atores do setor reconhecem a falta de oportunidades de promoção no trabalho em supermercados, como no discurso de um diretor de supermercado que avalia o trabalho na operação de caixa como algo 
que não favorece o desenvolvimento ou não contribui para a construção de uma carreira profissional.

Dejours (2009) afirma que a ação do reconhecimento através do trabalho possibilita o desenvolvimento da identidade, que é a base da saúde mental, e a aquisição de mais resistência psíquica face aos demais desafios da vida. Contudo, há organizações do trabalho que são destrutivas a esta dinâmica de contribuição-retribuição.

\section{Conclusão}

Esta pesquisa mostrou a necessidade de melhorias nas condições e organização do trabalho das operadoras de caixa. Os princípios organizacionais que negligenciam a saúde mental acabam por resultar na erosão do lugar reservado à subjetividade e à vida no trabalho. O que se vê como consequência é o agravamento das patologias mentais relacionadas ao trabalho, o aparecimento de novas patologias e até os suicídios no próprio local de trabalho (Dejours, 2012).

Toda pressão e cobrança vividas pelas operadoras não se reduzem somente às horas efetivas de trabalho, podendo se expandir para além do contexto laboral e invadir outros momentos da vida privada. As operadoras pensam no trabalho mesmo depois de terem encerrado o expediente ou mesmo depois de não trabalharem mais no supermercado. A estas colocações podemos relacionar a "contaminação" do tempo fora do trabalho, pois o tempo no trabalho e o tempo fora do trabalho acabam formando um continuum difícil de ser dissociado. Assim, as angústias vivenciadas na relação com o trabalho acabam se prolongando para fora dele.

É necessário discutir a divisão sexual do trabalho presente no supermercado, uma vez que ela limita as oportunidades de promoção das trabalhadoras, dificulta o aprendizado de outras atividades, instrumentaliza o corpo da trabalhadora e também a deixa mais vulnerável às práticas de assédio sexual no trabalho, contribuindo para o aumento das vivências de sofrimento, medo e submissão. Estudos que contemplem as questões de gênero no mundo do trabalho são de grande relevância, uma vez que as mulheres representam importante contingente da força de trabalho no Brasil. A forte discriminação que incide sobre o trabalho feminino acaba por contribuir para que as trabalhadoras sejam vulneráveis às várias formas de violência no contexto laboral, como o assédio moral (Figueiredo, 2012).

Uma análise do lugar de mulheres e homens no mercado de trabalho é indispensável para compreender o status de ambos os sexos na sociedade. $O$ trabalho encontra-se no centro das relações de gênero, e o contrário também é verdade: o gênero é elemento fundamental que regula as relações laborais (Maruani, 2018). Neste estudo, evidenciou-se a necessidade de intervenções na organização do trabalho de operadoras de caixa de supermercado, a fim de promover a manutenção da saúde mental destas trabalhadoras. Para tanto, as constatações desta pesquisa podem, por exemplo, servir de indicativos para que o setor de Recursos Humanos dos supermercados estruture ações de reconhecimento e promoção funcional, melhoria da comunicação entre chefias e subordinadas, oferta de suporte psicológico às funcionárias quanto às dificuldades vivenciadas no atendimento aos clientes, promoção de uma relação mais humanizada entre os funcionários de forma geral, combate ao assédio sexual no trabalho, dentre tantas outras ações que podem ser pensadas.

Dejours (2009) sublinha que as formas de organização do trabalho podem e devem ser questionadas, pois elas não são fruto de uma fatalidade ou um destino imutável no mundo do trabalho. Pois, toda organização do trabalho existe porque é validada, sendo, portanto, uma construção humana. Se o trabalho pode gerar sofrimento, também pode proporcionar a autorrealização e a emancipação. Assim, tudo depende da vontade coletiva de reencantar o trabalho. 


\section{Referências}

Antunes, R. (2018). O privilégio da servidão: o novo proletariado de serviços na era digital. Boitempo.

Bardin, L. (2011). Análise de conteúdo. Edições 70.

Barel, Y., \& Frémeaux, S. (2010). Organisation du travail et démarche qualité: le cas du secteur caisses d'un hypermarché. Revue de gestion des ressources humaines, 3(77), 22-37. https://www.cairn.info/revue-degestion-des-ressources-humaines-2010-3-p-22.htm

Barreto, M. (2014). Violência, assédio moral e sexual no trabalho. In A. M. Mendes, R. D. Moraes, \& A. R. C. Merlo (Orgs.), Trabalho e sofrimento: práticas clínicas e políticas (pp. 139-154). Juruá.

Bauer, W. M., \& Gaskell, G. (Orgs.) (2011). Pesquisa qualitativa com texto, imagem e som: um manual prático (9ª ed.). Vozes.

Bendassolli, P. F. (2009). Psicologia e trabalho: apropriações e significados. Cengage Learning.

Bendassolli, P. F., \& Soboll, L. A. P. (2011). Clínicas do trabalho: novas perspectivas para a compreensão do trabalho na atualidade. Atlas.

Benquet, M., \& Nathalie, M. (2009). Le refus d'encaisser. Travail, genre et sociétés, 21(1), 9-24.

Cardoso, D. T. (2015). A mulher e o trabalho: o cotidiano das trabalhadoras dos supermercados [Dissertação de mestrado, Universidade Federal de Goiás].

Dejours, C. (1980). Travail: usure mentale. Essai de psychopathologie du travail. Le Centurion.

Dejours, C. (2000). A banalização da injustiça social (3ํㅡㄹ. ed.). FGV.

Dejours, C. (2004). Subjetividade, trabalho e ação. Revista Produção, 14(3), 27-34.

Dejours, C. (2007). Psicodinâmica do trabalho na pós-modernidade. In A. M. Mendes, S. C. C. Lima, \& E. P. Facas (Orgs.), Diálogos em Psicodinâmica do Trabalho (pp. 13-26). Paralelo 15.

Dejours, C. (2009). Entre o desespero e a esperança: como reencantar o trabalho? Revista CULT, 139(12), 49-53.

Dejours, C. (2012). Trabalho vivo. Trabalho e emancipação (tomo II). Paralelo 15.

Dejours, C. (2015). A loucura do trabalho: estudo de psicopatologia do trabalho (6 $6^{\mathrm{a}}$ ed.). Cortez-Oboré.

Diniz, M. I. (2014). Mulheres como eu, mulheres como as outras: desvelando o assédio moral e sexual no âmbito do trabalho das comerciárias do estado do Rio Grande do Norte [Tese de doutorado, Universidade Estadual do Rio de Janeiro].

Falquet, J. (2016). Transformações neoliberais do trabalho das mulheres. In A. R. P. Abreu, H. Hirata, \& M. R. Lombardi (Orgs.), Gênero e trabalho no Brasil e na França: perspectivas interseccionais (pp. 37-46). Boitempo.

Figueiredo, P. M. (2012). Assédio moral contra mulheres nas organizações. Cortez.

Flores, V. D. C., \& Moura, E. P. G. (2018). Significados de trabalho, prazer e sofrimento no ofício de agentes funerários. Revista Psicologia: Organizações e Trabalho, 18(1), 326-334. http://dx.doi.org/10.17652/rpot/2018.1.13337

Freud, S. (2014). O futuro de uma ilusão. In S. Freud, Obras completas de Freud. Inibição, Sintomas e Angústias e outros textos (1926-1929). Companhia das Letras. Trabalho Original publicado em 1926-1929

Gomes, D. R., Sperandio, H. V., Guimarães, P. P., \& Fiedler, N. C. (2011). Análise ergonômica do posto de trabalho de operadores de caixa no supermercado BC. In XIV Encontro Latino Americano de Iniciação Científica, Alegre.

Heloani, R., \& Lancman, S. (2004). Psicodinâmica do Trabalho: o método clínico de intervenção e investigação. Revista Produção, 14(3), 77-86. https://doi.org/10.1590/S0103-65132004000300009

Hirata, H., \& Kergoat, D. (2007) Novas configurações da divisão sexual do trabalho. Cadernos de pesquisa, 37(132), 595-609. 
Martins, H. E., Montezeli, J. H., \& Pugin, A. P. (2010). O enfermeiro do trabalho e o transtorno depressivo em operadores de caixa de supermercado. Revista de Enfermagem UFPE, 4(2), 691-698.

Maruani, M. (Org.). (2018). Je travaille, donc je suis. Perspectives féministes. Éditions La Découverte.

Mendes, A. M. (2007). Psicodinâmica do trabalho: teoria, método e pesquisas. Casa do Psicólogo.

Moraes, R. D., Schlindwein, V. D. C., Ghizoni, L. D., Oliveira, P. de T. R., Nina, S. de F. M., Santana, P. M., Mélou, A. C. S. de A., \& Monteiro, T. M. (2019) Experiências em psicodinâmica do trabalho na Amazônia: escuta do sofrimento no trabalho. In J. K. Monteiro, R. D. Moraes, L. G. Freitas, L. D. Ghizoni, \& E. P. Facas (Orgs.), Trabalho que adoece: resistências teóricas e práticas (pp. 209-251) [recurso eletrônico]. Editora Fi. https://www.editorafi.org/650trabalho

Organização Internacional do Trabalho. (2018). Perspectivas Sociales y del Empleo en el Mundo: avance global sobre las tendencias del empleo femenino 2018. https:/www.ilo.org/global/research/global-reports/weso/trends-forwomen2018/WCMS_619603/lang--es/index.htm

Santos, L. M. (2004). Avaliação da carga de trabalho em operadoras de caixa de supermercado: um estudo de caso [Dissertação de mestrado, Universidade Federal do Rio Grande do Sul].

Scott, J. (1995). Gênero: uma categoria útil para a análise histórica. SOS Corpo.

Seligmann-Silva, E. (2011). Trabalho e desgaste mental: o direito de ser dono de si mesmo. Cortez.

Soares, A. (2014). O preço de um sorriso: as emoções no trabalho, desafios para a saúde das trabalhadoras e dos trabalhadores. In J. A. Oliveira, \& M. Matsuo (Orgs.), O trabalho emocional e o trabalho de cuidado (pp. 13. 25). Fundacentro.

Teixeira, C. S., Torres, M. K., Moro, A. R. P., \& Merino, E. A. D. (2009). Fatores associados ao trabalho de operadores de checkout: investigação das queixas musculoesqueléticas. Produção, 19(3), 558-568. https://doi.org/10.1590/S0103-65132009000300012

Trelha, C. S., \& Carregaro, R. L. (2017). Análise de posturas e movimentos de operadores de checkout de supermercado. Fisioterapia e Movimento. Curitiba, 20(1), 45-52.

Waelli, M., \& Fache, P. (2013). La régulation de l'emploi dans les hypermarchés français: Stratégies de mobilisation de la main-d'œuvre et rapports à l'activité aux caisses. Travail et emploi, 136(4), 35-47. https://www.cairn.info/revue-travail-et-emploi-2013-4-page-35.htm

Endereço para correspondência ericsemk@gmail.com
Recebido em: 07/10/2020

Revisado em: 15/10/2021

Aprovado em: 18/10/2021 